\title{
Computational analysis of sterol ligand specificity of the Niemann Pick C2 protein
}

\author{
Vasanthanathan Poongavanam ${ }^{\S}$, Jacob Kongsted ${ }^{\S}$ and Daniel Wüstner ${ }^{\dagger}$ ** \\ ${ }^{\S}$ Department of Physics, Chemistry and Pharmacy and ${ }^{\dagger}$ Department of Biochemistry and Molecular \\ Biology, University of Southern Denmark, DK-5230 Odense M, Denmark. *Address correspondence \\ to: Daniel Wüstner, Tel. +45-6550-2405, Fax +45-6550-2405, e-mail: wuestner@bmb.sdu.dk
}

\section{SUPPLEMENTARY INFORMATION}

Figure Legends

SF1: Initial conformation of protein-ligand complex used for MD simulations, number indicates the normal (1) and constrained (2) binding pose.

SF2: Calculated physicochemical properties of fragments of estradiol and U186.

SF3: The energy contributions (obtained from decomposition of binding energy) between each residue of NPC2 and the sterols are plotted.

SF4: Sequence comparison of mammalian NPC2 (residues that marked with red color are chosen for computational mutational study as these mutations have been shown to be clinically relevance.

SF5: Comparison of decomposition energies for important residues from different simulations of CHACE and U186 is plotted.

SF6: Comparison of residues flexibility upon various mutations and wild type (A), and comparison of backbone RMSD (B).

SF7: Residues backbone loop flexibility upon mutating Pro24 into Ala24 in comparison to wildtype NPC2 in the presence of cholesterol.

\section{Table Legends}

ST1 The correlation between experimental activity (relative \% of inhibition) with physicochemical properties of sterols,

ST2. Summary of energies obtained from MM-PB/SA methods using various MD run

ST3 The correlation between experimental activity (relative $\%$ of inhibition) with physicochemical properties of sterols

ST4 The correlation between experimental activity and residues decomposition of binding energies from the MM-PBSA calculation $(\mathrm{kcal} / \mathrm{mol})$ is provided. 
SF1. Initial conformation of protein-ligand complex used for MD simulations, number indicates the normal (1) and constrained (2) binding pose.

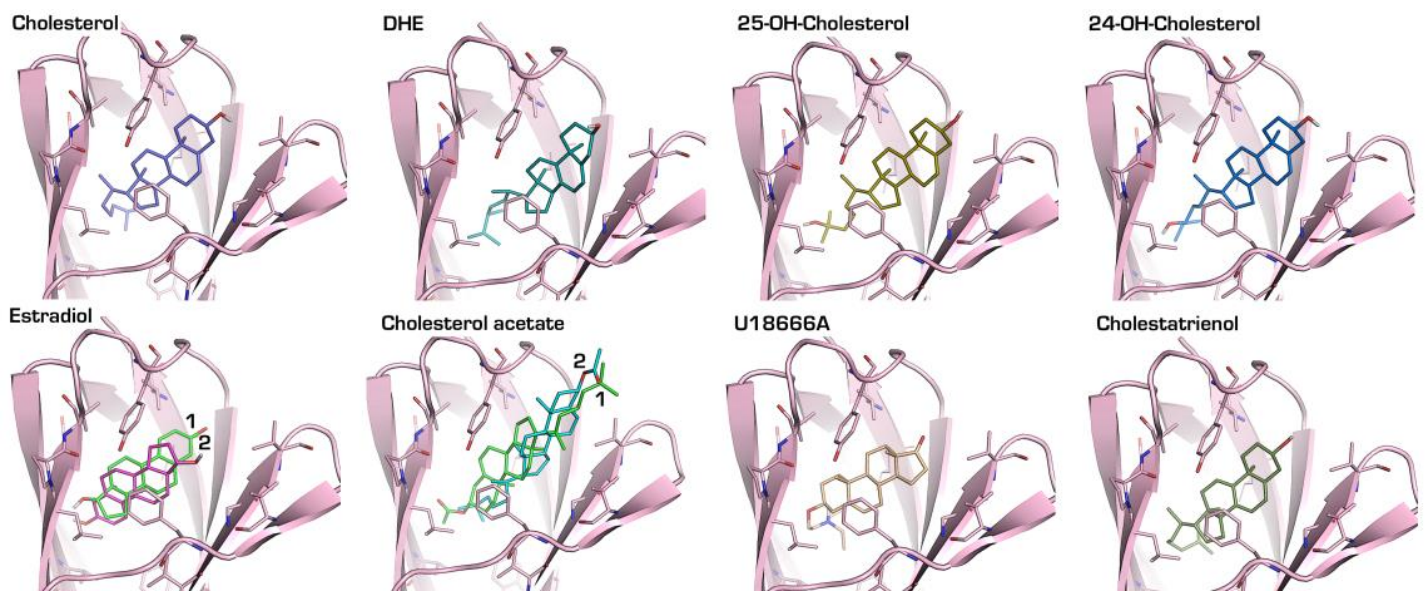


SF2. Calculated physicochemical properties of fragments of estradiol and U186
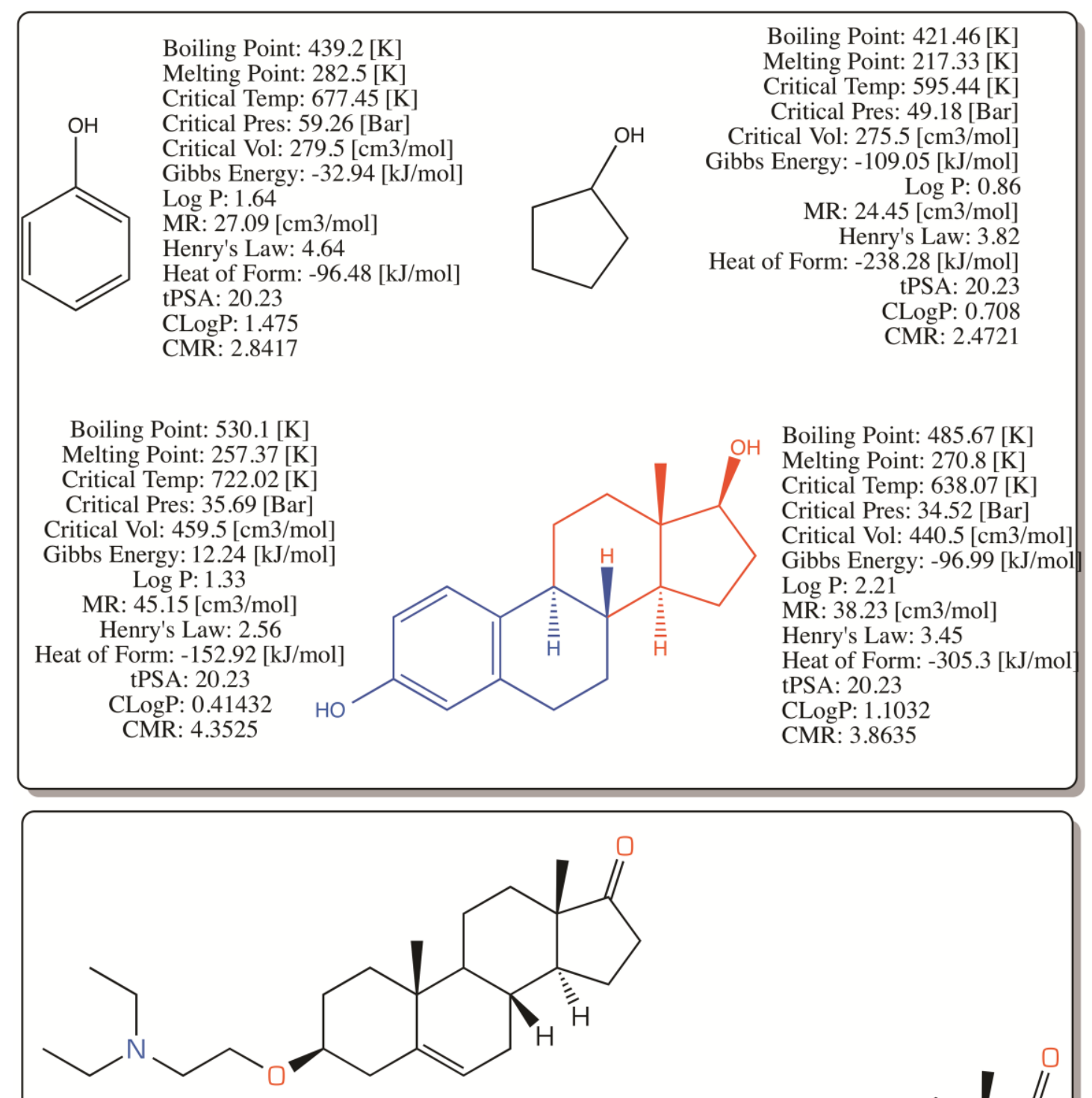

Boiling Point: 917.87 [K] Melting Point: $600.69[\mathrm{~K}]$ Critical Temp: 895.28 [K] Critical Pres: 11.79 [Bar] Critical Vol: $1246.5[\mathrm{~cm} 3 / \mathrm{mol}]$ Gibbs Energy: 219.24 [kJ/mol]

$$
\text { Log P: } 4.75
$$

MR: 116.44 [cm3/mol]

Henry's Law: 6.99

Heat of Form: $-465.21[\mathrm{~kJ} / \mathrm{mol}]$ tPSA: 29.54

CLogP: 3.0006

CMR: 11.5949

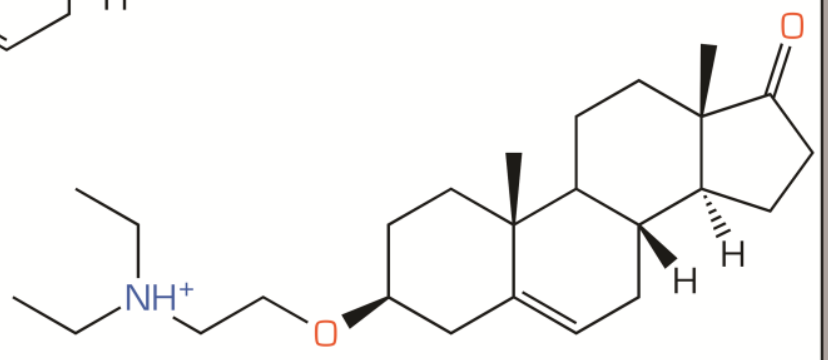

Log P: 4.21

tPSA: 30.74

CLogP: 3.30104

CMR: 11.6836 
SF3 The energy contributions (obtained from binding energy decomposition) between each residue of NPC2 and the sterols are plotted.

Residues

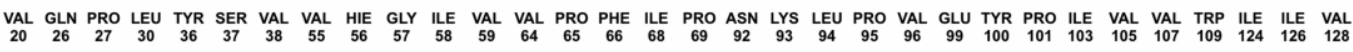

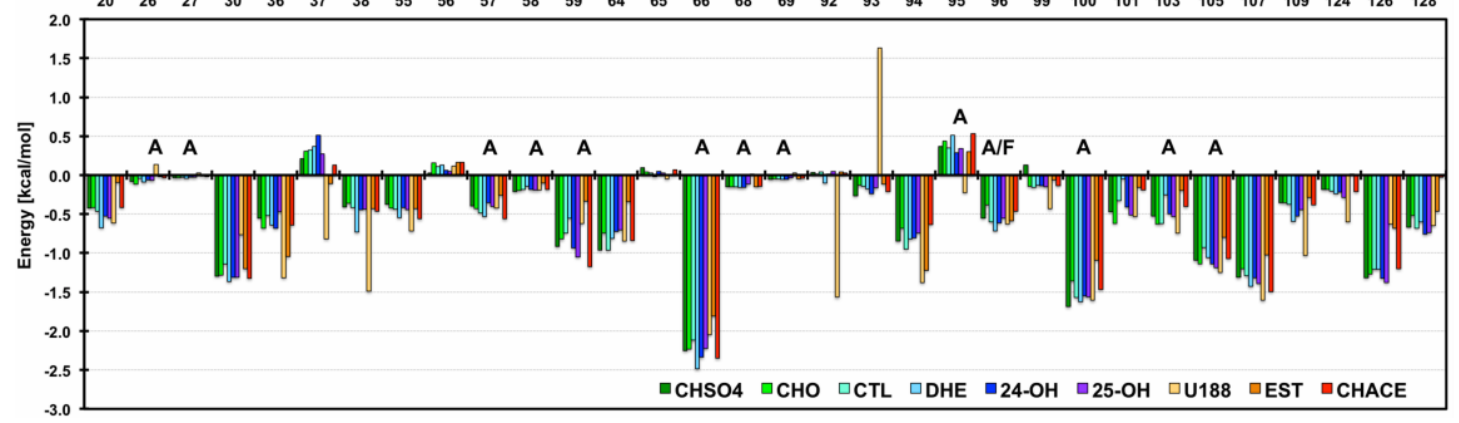

SF4: Sequence comparison of mammalian NPC2 (residues that marked with red color are chosen for computational mutational study as these mutations have been shown to be clinically relevance.
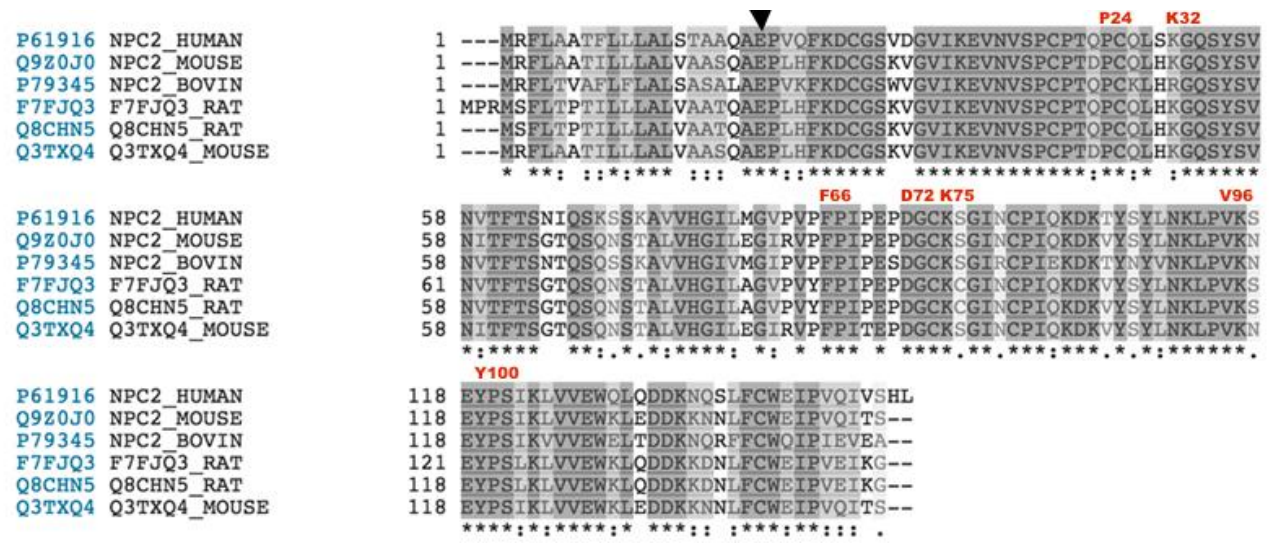
SF5. Comparison of decomposition energies for important residues from different simulations of CHACE and U186 is plotted. For CHACE 'Original' indicates the starting conformation of the ligand in the binding pose, while 'Refined' means the opposite orientation of the ligand in the pocket of NPC2. For U18666A, 'Original' indicates the deprotonated ligand in the binding pose, while 'Refined' means the protonated ligand in the pocket of NPC2.

\section{Residues $\quad$ Refined $\square$ Original}

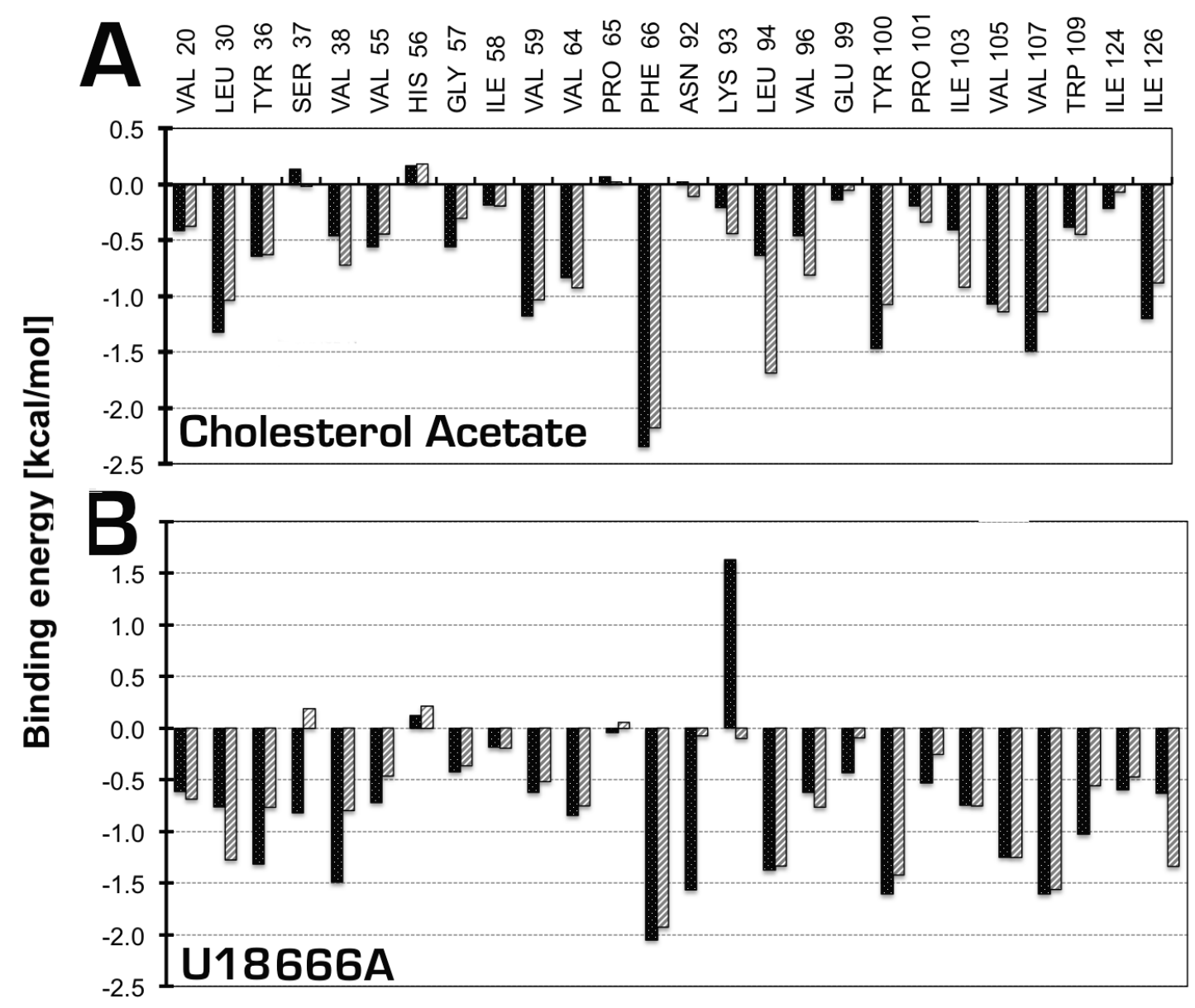


SF6: Comparison of residues flexibility upon various mutations and wild type (A) and comparison of backbone RMSD (B). The molecular flexibility of the protein backbone of NPC2 wild type and the indicated point mutations in the presence of cholesterol as ligand was calculated as B-factor relative to the start conformation and decomposed as function of residues (A, compare to Figure $2 \mathrm{C}$ ) or as function of simulation time (B, compare Figure 5A). 

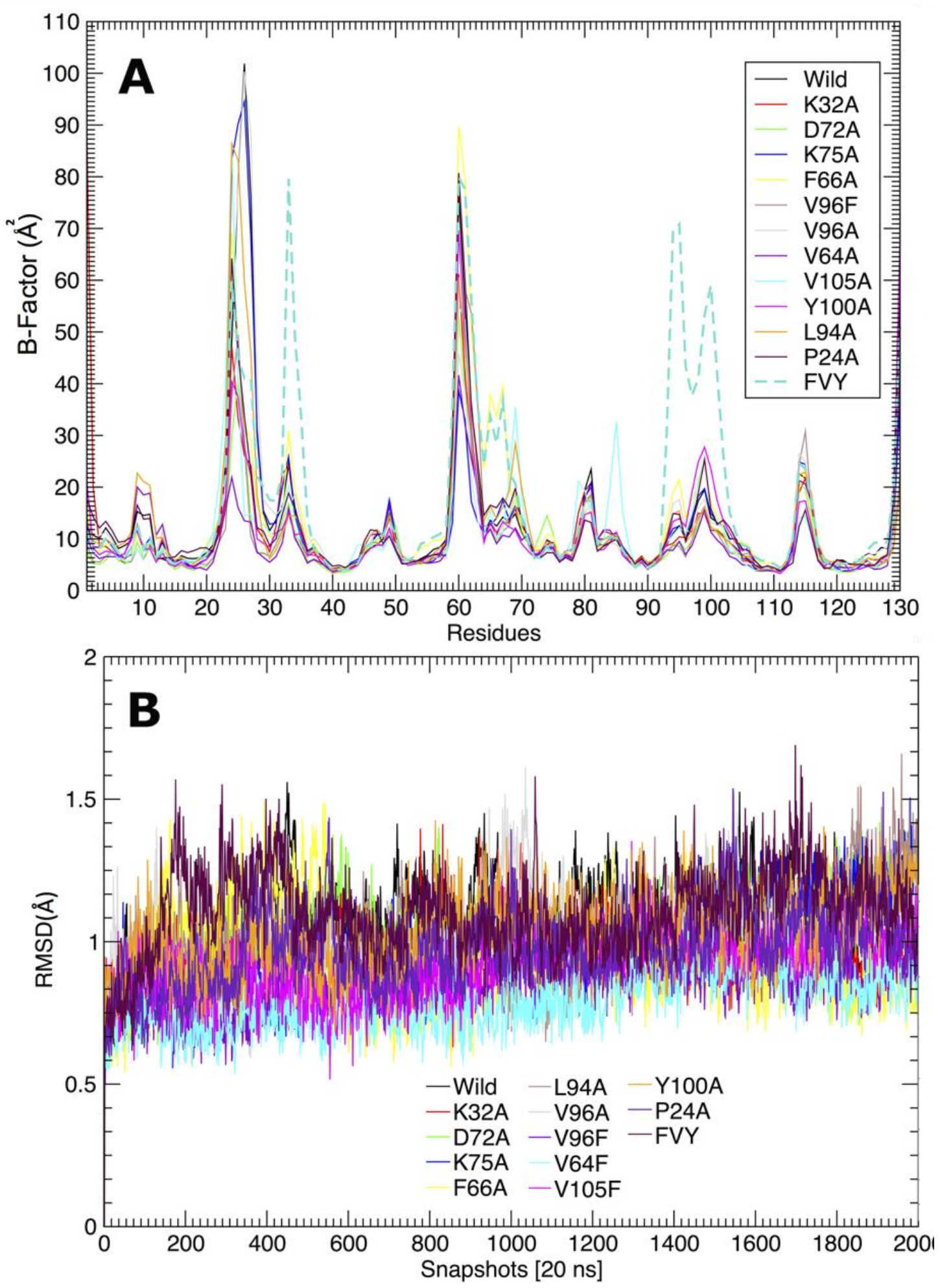

SF7: Residues backbone loop flexibility upon mutating Pro24 into Ala24 in comparison to wildtype $\mathrm{NPC2}$ in the presence of cholesterol. B-factor (A) and residue location (B) in NPC2 is shown. The molecular flexibility of the protein backbone of NPC2 in the loop region formed by residues 23-27 for the wild type and the P24A mutant NPC2 are indicated. 

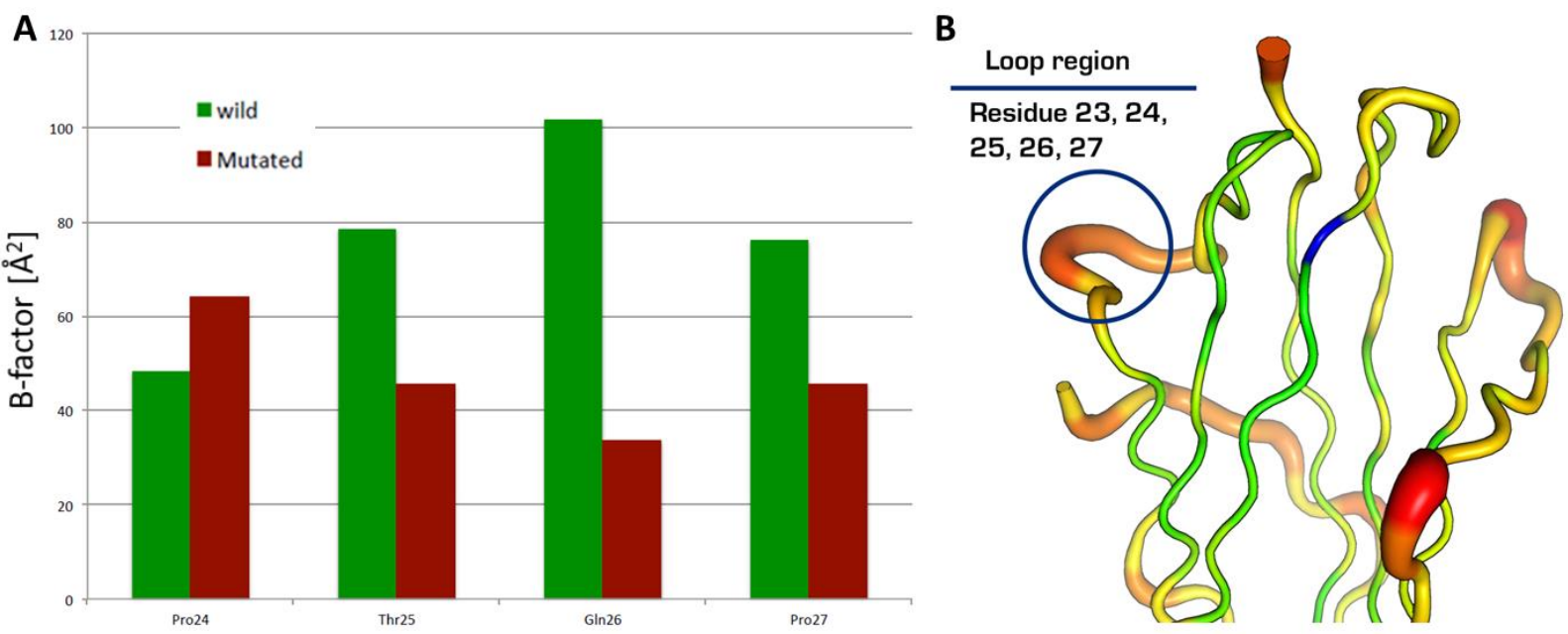
ST1. Summary of important residues B-factor $\left(\AA^{2}\right)$ and experimental binding affinities for sterols.

\begin{tabular}{|c|c|c|c|c|c|c|c|c|c|c|c|c|c|}
\hline Residues & CHSO4 & $\mathrm{CHO}$ & DHE & $\mathrm{CTL}$ & $24-\mathrm{OH}$ & $25-\mathrm{OH}$ & $\mathrm{U} 186$ & CHACE & APO & EST & $\mathrm{R} 2$ & Outlier $^{1}$ & $\mathrm{R}^{2}$ after Outlier \\
\hline Activity (\%) & 100 & 90 & 90 & 90 & 50 & 50 & 20 & 0 & - & 10 & & & \\
\hline PRO 24 & 25.03 & 17.23 & 30.56 & 29.10 & 70.77 & 76.45 & 76.96 & 70.47 & 27.74 & 67.99 & 0.39 & Apo & 0.77 \\
\hline LEU 30 & 5.78 & 6.98 & 6.47 & 7.53 & 7.09 & 9.85 & 9.17 & 11.07 & 10.80 & 12.32 & 0.73 & $\mathrm{Nil}^{3}$ & - \\
\hline HIE 31 & 6.91 & 8.20 & 8.44 & 8.69 & 7.10 & 12.57 & 11.87 & 12.30 & 19.74 & 18.27 & 0.58 & Nil & - \\
\hline ARG 32 & 9.14 & 10.35 & 12.41 & 11.46 & 8.93 & 15.08 & 29.59 & 19.82 & 25.72 & 22.63 & 0.72 & Nil & - \\
\hline GLY 33 & 15.20 & 14.72 & 17.64 & 14.68 & 16.50 & 15.56 & 51.82 & 20.58 & 39.35 & 44.49 & 0.51 & Nil & - \\
\hline GLN 34 & 10.73 & 13.98 & 10.64 & 12.45 & 10.98 & 10.98 & 26.50 & 13.62 & 23.10 & 33.75 & 0.40 & Nil & - \\
\hline VAL 96 & 7.09 & 9.17 & 8.09 & 9.42 & 8.04 & 8.57 & 13.93 & 9.71 & 22.10 & 24.72 & 0.41 & Nil & - \\
\hline LYS 97 & 9.29 & 12.37 & 13.12 & 10.97 & 11.78 & 10.61 & 16.61 & 12.80 & 23.35 & 32.70 & 0.30 & EST & 0.45 \\
\hline ASN 98 & 12.57 & 14.03 & 18.69 & 14.49 & 13.99 & 16.12 & 24.97 & 21.49 & 22.50 & 29.71 & 0.57 & Nil & - \\
\hline GLU 99 & 16.06 & 17.91 & 22.57 & 18.69 & 17.66 & 19.66 & 26.50 & 23.08 & 26.81 & 46.39 & 0.30 & Est & 0.60 \\
\hline TYR 100 & 12.18 & 13.96 & 17.38 & 15.25 & 12.92 & 14.73 & 18.85 & 17.94 & 25.45 & 39.76 & 0.30 & Est & 0.50 \\
\hline PRO 101 & 11.51 & 14.55 & 17.60 & 14.40 & 12.00 & 13.67 & 19.43 & 21.90 & 26.24 & 37.10 & 0.41 & Est & 0.58 \\
\hline SER 102 & 10.61 & 15.21 & 12.29 & 12.46 & 10.73 & 12.42 & 13.94 & 19.60 & 24.81 & 26.79 & 0.46 & Nil & - \\
\hline ILE 103 & 10.41 & 11.03 & 9.58 & 8.86 & 9.21 & 9.08 & 12.05 & 14.32 & 17.80 & 18.67 & 0.51 & Nil & - \\
\hline LYS 104 & 8.06 & 8.62 & 8.30 & 8.08 & 8.04 & 8.26 & 10.76 & 8.87 & 9.80 & 11.49 & 0.46 & Nil & - \\
\hline
\end{tabular}

${ }^{1}$ Points that deviates from the linear line in the correlation; ${ }^{2}$ Correlation coefficient after removal of outlier; ${ }^{3}$ No outliers found into order to improve the correlations, that means all points are segregated, no correlation found. 
ST2. Summary of energies obtained from MM-PB/SA methods using various

MD runs. Values are provided from all MM-PBSA calculations at pH 7.0. Note that for the second run for U18866, the protonated form was used.

\begin{tabular}{|c|c|c|c|c|c|c|c|c|c|c|}
\hline & Compound & $\mathrm{CHO}$ & CHSO4 & DHE & CTL & $240 \mathrm{H}$ & $25 \mathrm{OH}$ & EST & U18866 & CHACE \\
\hline & IC50 $(\mu \mathrm{M})$ & 90 & 100 & 90 & 90 & 50 & 50 & 10 & 20 & 0 \\
\hline \multirow{5}{*}{ 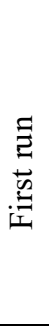 } & $\mathrm{E}_{\mathrm{vdW}}$ & -49.67 & -50.39 & -53.62 & -48.27 & -51.21 & -50.32 & -36.58 & -54.65 & -53.03 \\
\hline & $\mathrm{E}_{\text {Ele }}$ & -0.09 & 6.06 & -2.14 & -0.51 & -1.10 & -1.68 & -4.58 & -2.03 & -5.24 \\
\hline & $\Delta \mathrm{G}_{\mathrm{solv}}$ & -49.77 & 31.65 & 43.16 & 35.74 & 44.66 & 44.38 & 41.33 & 42.34 & 47.74 \\
\hline & $\Delta \mathrm{G}_{\mathrm{gas}}$ & 32.83 & -44.32 & -55.77 & -48.78 & -52.31 & -52.00 & -41.17 & -56.68 & -58.28 \\
\hline & $\Delta \mathrm{G}$ & $\begin{array}{c}-16.94 \\
\pm 3.1\end{array}$ & $\begin{array}{c}-15.88 \\
\pm 3.0\end{array}$ & $\begin{array}{c}-12.61 \\
\pm 3.8\end{array}$ & $\begin{array}{c}-13.04 \\
\pm 3.4\end{array}$ & $\begin{array}{c}-7.64 \\
\pm 3.1 \\
\end{array}$ & $\begin{array}{c}-7.61 \\
\pm 3.4\end{array}$ & $\begin{array}{l}0.16 \\
\pm 4.1 \\
\end{array}$ & $\begin{array}{c}-14.34 \\
\pm 3.7\end{array}$ & $\begin{array}{c}-10.54 \\
\pm 3.5\end{array}$ \\
\hline \multirow{5}{*}{ 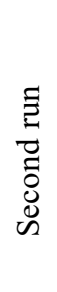 } & $\mathrm{E}_{\mathrm{vdW}}$ & - & - & - & - & - & - & -32.10 & -54.26 & -50.46 \\
\hline & $\mathrm{E}_{\text {Ele }}$ & - & - & - & - & - & - & -4.49 & -14.92 & 0.55 \\
\hline & $\Delta \mathrm{G}_{\mathrm{gas}}$ & - & - & - & - & - & - & 34.33 & 63.16 & -49.90 \\
\hline & $\Delta \mathrm{G}_{\text {Solv }}$ & - & - & - & - & - & - & -36.60 & -69.18 & 37.81 \\
\hline & $\Delta \mathrm{G}$ & - & - & - & - & - & - & $\begin{array}{l}-2.26 \\
\pm 3.0\end{array}$ & $\begin{array}{c}-6.01 \\
\pm 4.6\end{array}$ & $\begin{array}{c}-12.0 \\
\pm 3.1\end{array}$ \\
\hline
\end{tabular}


ST3 The correlation between experimental activity (relative \% of inhibition) with physicochemical properties of sterols

\begin{tabular}{|c|c|c|c|c|c|c|c|c|c|}
\hline Title & Activity & MW & $A \log P$ & HBA & HBD & $\mathrm{RB}$ & HAC & MR & Polar \\
\hline CHSO4 & 100 & 465.7 & 6.5 & 1.0 & 0.0 & 7.0 & 32.0 & 128.3 & 51.1 \\
\hline $\mathrm{CHO}$ & 90 & 386.7 & 7.4 & 1.0 & 1.0 & 5.0 & 28.0 & 120.6 & 47.4 \\
\hline CTL & 90 & 382.6 & 6.9 & 1.0 & 1.0 & 5.0 & 28.0 & 122.3 & 46.4 \\
\hline DHE & 90 & 394.6 & 6.7 & 1.0 & 1.0 & 4.0 & 29.0 & 128.0 & 47.8 \\
\hline $25 \mathrm{OH}$ & 50 & 402.7 & 6.0 & 2.0 & 2.0 & 5.0 & 29.0 & 122.5 & 48.0 \\
\hline $24 \mathrm{OH}$ & 50 & 402.7 & 6.2 & 2.0 & 2.0 & 5.0 & 29.0 & 122.2 & 48.0 \\
\hline U18 & 20 & 387.6 & 4.4 & 2.0 & 0.0 & 6.0 & 28.0 & 116.9 & 45.1 \\
\hline EST & 10 & 272.4 & 3.8 & 2.0 & 2.0 & 0.0 & 20.0 & 79.6 & 34.7 \\
\hline $\mathbf{R}^{2}$ & & 0.4 & 0.8 & 0.8 & 0.1 & 0.3 & 0.5 & 0.5 & 0.5 \\
\hline
\end{tabular}

\section{Note:}

$\mathrm{MW}=$ Molecular weight, $\mathrm{ALogP}=$ Ghose-Crippen-Viswanadhan octanol-water partition coefficient (ALogP), HBA=Number of hydrogen bond acceptor, $\mathrm{HBD}=$ Number of hydrogen bond donor, $\mathrm{RB}=$ Number of rotatable bonds, $\mathrm{HAC}=$ Number of heavy atoms, $\mathrm{MR}=$ Molar refractivity, Polar=Polarity. 
ST4 The correlation between experimental activity and residues decomposition of binding energies from the MM-PBSA calculation ( $\mathrm{kcal} / \mathrm{mol})$ is provided.

\begin{tabular}{lccccccc}
\hline Residues & $\%$ & Tyr36 & Val64 & Phe66 & Leu94 & Pro95 & Ile126 \\
\hline CHSO4 & 100 & -0.552 & -0.96 & -2.253 & -0.849 & 0.371 & -1.318 \\
CHO & 90 & -0.685 & -0.747 & -2.231 & -0.682 & 0.437 & -1.269 \\
CTL & 90 & -0.516 & -0.964 & -2.12 & -0.95 & 0.347 & -1.208 \\
DHE & 90 & -0.643 & -0.812 & -2.487 & -0.819 & 0.513 & -1.206 \\
24-OH & 50 & -0.682 & -0.721 & -2.338 & -0.807 & 0.286 & -1.323 \\
25-OH & 50 & -0.47 & -0.704 & -2.226 & -0.741 & 0.344 & -1.378 \\
U186 & 20 & -1.317 & -0.845 & -2.048 & -1.378 & -0.222 & -0.63 \\
EST & 10 & -1.048 & -0.344 & -1.809 & -1.221 & 0.298 & -0.681 \\
CHACE & 0 & -0.64 & -0.837 & -2.349 & -0.635 & 0.535 & -1.201 \\
& $\mathbf{R}^{2}$ & $\mathbf{0 . 5 6}$ & $\mathbf{0 . 4 9}$ & $\mathbf{0 . 4 5}$ & $\mathbf{0 . 5 1}$ & $\mathbf{0 . 4 5}$ & $\mathbf{0 . 5 6}$
\end{tabular}

